\title{
TRANSFORMING THE HEALTHCARE SYSTEM: THE PUBLIC-PRIVATE HEALTHCARE DICHOTOMY IN INDIA IN THE ERA OF DIGITAL HEALTH
}

\author{
Liji Samuel
}

\author{
The National University of Advanced Legal Studies (NUALS), Kerala, India
}

\begin{abstract}
Digital health initiatives have become popular in all jurisdictions across the globe. The digital health move, though it is envisioned as a cost-effective way to ensure the availability of health care services especially for the people who live in rural areas, its success depends on the response of the health care system and the state control and regulation. India lacks a comprehensive statesponsored or state-regulated health care system and more than 70 percent of people utilise the private sector medical services. In this backdrop, the implementation of the National Digital Health Mission (NDHM), announced by the Government of India very recently, will be critical. Thus, this research paper strives to bring out the public-private disjunction in the availability and utilisation of public and private health care facilities, issues of health care financing and legal regulation of clinical establishments in the public and private sector. This study uses the doctrinal method and analyses the Five-Year Plans, National Sample Survey Reports, National Health Profile, National Health Accounts Estimates for India and other Government Reports and independent studies to detail the public-private dichotomy. However, this study finds limitations in presenting the current position of private health care service providers due to the unavailability of updated authoritative government reports/ studies/ surveys. On reviewing the currents trends in the public and private health care sector, the study finds that the private sector has surpassed the public sector in all means, including health provisioning, utilisation, and financing. The NDHM is a laudable initiative to ensure affordable health care to millions of people in India. However, any move to implement it, leaving the fundamental issue of deep-rooted public-private dichotomy existing in the healthcare sector will be detrimental. It will result in a digital divide in the public and private healthcare sector and gross violation of patients' rights and mismanagement of health information.
\end{abstract}

Keywords: digital health, National Digital Health Mission, private healthcare sector, utilisation of healthcare service

\section{Introduction}

India is one of the fastest-growing healthcare markets. The Indian healthcare market is predicted to grow Rs.8.6 trillion by 2020 (Healthcare Industry in India.). More interestingly it is one of the most privatised healthcare systems in the world. It encompasses different types of providers ranging from small to corporate hospitals in the public and private sector, offering services under different systems of medicine. Since independence through Five - Year Plans, the successive governments devised various public health measures. However, a comprehensive and structured health care system has invariably been a low priority for all governments in India. Hence as part of the structural adjustment programmes, the government opened up even the core public sectors for the private players and it led to the privatisation and corporatisation of the Indian healthcare sector. Currently, the healthcare system is going to witness the digitalisation of healthcare services. The digitalisation of healthcare is increasingly being promoted for cost-effective, real-time, quality service and as a measure to implement the concept of Universal Health Care. The Ministry of Health and Family Welfare has taken steps to initiate various digital health programmes such as the National Health Portal, Electronic Medical Records, mHealth, etc. since 2015. Though the digital health programme has the potential to emerge as the next generation 
health care service for millions of people in India, the public-private disjunction existing in the health service sector at different levels including the infrastructural facilities, utilisation pattern, health expenditure and legal regulations are posing severe constraints on NDHM.

\section{Objective and Methodology}

This research paper aims to explore the public-private dichotomy existing in the Indian health care system and it intends to analyses the implications of the public-private dichotomy on the recently announced digitalisation of the healthcare programme 'National Digital Health Mission'. The study follows the doctrinal method and has adopted exploratory and descriptive research methods to analyse the stated objectives. The study has reviewed various Government reports including the National Sample Survey, Five Year Plans, National Health Profile, etc and other published secondary sources of literature.

\section{Equity in Healthcare: The Promising Digital Health Solutions}

Digital health solutions have transformed the conventional notions of health care systems. It has made farreaching changes in patient care, medical technologies, hospital management, medical research, remote patient care, etc. It is characterised by a fusion of technologies that is blurring the lines between the physical, digital, and biological spheres'(Schwab Klaus). Due to the large-scale intrusion of digital technologies, the health care institutions in the government and private sector are investing heavily in digital health solutions to ensure patient-centred healthcare services. In 2019 the ' $\mathrm{m}$-Health Intelligence' reported that about $88 \%$ of healthcare institutions are investing in remote patient monitoring (RPM) technologies in the U.S. (McGrail Samantha). The remote patient monitoring technologies are providing practical ways to render medical care outside the traditional health care settings and facilitate tracking of patients' conditions, especially in underserved areas. The healthcare industry is also bombarded with sophisticated medical devices with cutting-edge technologies every day. Such devices offer various health services ranging from measuring blood pressure, stress, sleep quality, weight, heart rate, glucose level, automatic ECG etc. that had been provided by health care professionals in the traditional health care system earlier. The outbreak of COVID 19 pandemic set the scenario more favourable and the rate of digital health utilisation in the last six months was more than the previous 14 years. In a webinar on Digital Health, it was observed that more than 52 percent of a medical opinion is done on web browsing, more than 72 percent of appointments are given online nowadays('Digital Health: The Future Series II- Bridging the Gap: A.I.'s Role in Combating Inequalities in Health' Webinar Organised - Express Healthcare).

The digital health solutions are well recognised as a cogent way to address the limitations of healthcare systems. Various international conventions guarantee quality health care services to all people at an affordable price(U.N. Office of the High Commissioner for Human Rights (OHCHR, 2008). However, on its implementation, healthcare systems find difficulty in setting up adequate infrastructure and allocating enough resources. Health care systems are struggling badly to cater to the needs of the common man. There exists a wide gap in the availability and accessibility of quality medical care in middle and lower-income countries, including in India(World Health Organization, 2019). Realising the importance of revitalising health care governance, the World Health Organisation proposed various digital health programmes towards achieving the goals of Universal Health Coverage (UHC). In May 2018, the WHO member countries passed a resolution to develop a global strategy by WHO on digital health. The WHO published the 'WHO Guidelines: Recommendations on Digital Intervention for Health System Strengthening, as its first level of recommendations on digital health in 2019 (WHO Releases First Guideline on Digital Health Interventions). These guidelines recommended using digital technologies, including e-Health and m-health, to pursue the goals of Universal Health Coverage and the Sustainable Development Goals (SDGs)(World Health Organization, 2019). The WHO Guidelines propose to tap the benefits of digital technologies responsibly, ensuring the fundamental rights of patients, including the 
right to privacy and confidentiality. These changing trends at the global level have paved the way for adopting new strategic measures by many the middle and lower-income countries (Labrique et al., 2018).

\section{The National Digital Health Mission and the Changing Healthcare Landscape in India}

Since independence, the healthcare system has witnessed tremendous changes. With the announcement of the National Digital Health Mission (NDHM) by the Prime Minister on August 15, 2020 (Sharma Neetu Chandra), India made its first move towards laying a concrete foundation for digitalisation of the healthcare system. India is one of the fastest-growing digital markets across the globe, and it is considered that there was $90 \%$ of growth during 2014-17 in terms of digital adoption index (Digital Healthcare Market in India 2019 - Research and Markets). It is reported by the India Future Health Index 2019 that around 76\% of healthcare professionals use digital health records, and $46 \%$ of professionals use A.I. technologies within their medical practice (Singh, S. ). The widespread use of digital devices and growing digital literacy coupled with the e-government initiatives under the aegis of the 'Digital India' programmes have led to the implementation of digitalisation of various health care services at the government level since 2015.

In 2016 the Ministry of Health and Family Welfare designed a website, 'National Health Portal' as single point access for authenticated health information and an initiate to coordinate digital health programmes such as EHosptial, Electronic Health Records, My Health Records, m-Diabetes, Telemedicine etc. (National Health Portal of India, Gateway to Authentic Health Information). Along with these programmes, attempts have been made to bring policies and guidelines to support digital health programmes such as Electronic Health Records Standard 2016 and Telemedicine Practice Guidelines 2020. The NITI Aayog Report on 'Health System for a New India: Building Blocks'(NITI Aayog, 2019) and the recently adopted 'National Digital Health Blueprint'(Ministry of Health \& Family Welfare, 2019) were the significant Government level attempts to streamline digital health programmes. Finally, the government announced the much-awaited all encompassed version, the 'National Digital Health Mission (NDHM)'. It contains the following components such as national level Health ID card, Digidoctor, Health Facility Registry, Personal Health Records, e-pharmacy and Telemedicine (National Health Mission: National Digital Health Mission Rolled out on Pilot Mode in 6 Union Territories - Times of India). The National Health Authority (NHA) will design and implement NDHM, and the programme is proposed to rollout a pilot launch in Union Territories(National Health Mission: National Digital Health Mission Rolled out on Pilot Mode in 6 Union Territories - Times of India). These initiatives are further strengthened by the collaboration with the tech giant Google towards the 'Build for Digital India' project (Mathur, N.) and the development of a complete indigenous 5G solution (Aryan \& Mukul).

\section{The Public-Private Healthcare Dichotomy: An Analysis Changing Trends}

Unlike in other countries, the Indian healthcare system is fragmented, and it is a complex network of different service providers and systems of medicine under the government and private sector. India developed a three-tier healthcare system at the primary, secondary and tertiary levels. However, it lacks a comprehensive statesponsored robust healthcare structure as in the case of other countries like the U.K. or Canada (Government of India, 2013). Though the Indian healthcare initiatives were primarily based on the Bhore Committee report; it lost its connection nowadays. The Bhore Committee had recommended adopting a healthcare system to ensure medical care to all people irrespective of their capacity to pay and to ensure availability of medical services in the safe geographical reach of everyone through the state healthcare services (Bhore et al., 1946). In contrast to this, the Indian healthcare system moved to privatisation and corporatisation. The growth of the private sector is divided into four phases and is explained below. 


\section{I phase (1951 to 1982)}

This period is characterised by the dominance of the public sector and implementation of health policies and programmes through the Five Year Plans as India adopted its first health policy only in 1983 (Duggal, 2004). However, the availability of infrastructure facilities in the public sector during this period was much lesser than it was projected in the Five Year Plans (Government of India, 1961).

\section{II phase (1983 to 2001)}

The first National Health Policy (NHP) adopted in 1983 proposed for the first time the segmentation of the healthcare system for the poor and rich by creating a network of speciality and super-speciality services through private entities and to limit the government sector services to the poor and underprivileged(Ministry of Health and Family Welfare, 1983). This has coincided with the global recession and economic restructuring which ultimately led to reduced budget allocation and shrinking of the public health care system. The Private sector started to pick up its market by capitalising on the state deficiency in health provisioning(Vaidyanathan Baru).

\section{III phase (2002 to 2016)}

The private sector dominated during this period and the second National Health Policy (NHP) adopted in 2002 addressed the role and significance of the private healthcare sector and the need for adopting a proper regulation for the private sector. Though the NHP 2002 proposed to adopt statutory rules for the private health care sector, the Clinical Establishment (Registration and Regulation) Act was adopted only in 2010. By that time, the health care sector had moved to corporatisation, where multinational entities started to invest heavily in the Indian health care market.

\section{IV phase (2017 onwards)}

The fourth phase started with the third National Health Policy (NHP) adopted in 2017. It proposed the digitalisation of health care services by providing a secure network for the private and public sector entities to collaborate in health care management. Consequently, the government announced the National Digital Health Mission on August 15, 2020. Though India has taken a quantum leap in the health care service sector by promoting the digitalisation of healthcare, it will be puzzled by the unresolved public-private dichotomy in health care provisioning, financing and regulation.

\section{Understanding the Public-Private Dichotomy in the Indian Healthcare Landscape}

There exists an apparent disjunction in the public and private health care and are covered briefly under the following four headings.

\section{a. The Availability of Public-Private Healthcare Infrastructure}

The private sector was present even at the time of independence (1353 healthcare institutions)(Kumar, 2015). It started to expand during the 1990s. In the year 2000, the government allowed 100 percent Foreign Direct Investment in the hospital sector. Along with it, customs duty exemptions, subsidised land, loans and tax exemptions were also allowed to the private sector hospitals (Kumar, 2015). The decision to allow 100 percent FDI and opening up of the insurance sector attracted the corporate sector to invest in the Indian health care sector. The corporates like Apollo, Max Healthcare, Fortis etc. started to invest in hospital industry which led to the closure of many small and medium scale hospitals (Marathe et al., 2020) and the Indian health care sector moved slowly towards corporatisation. The growth of the private industry was unregulated and uncontrolled at 
all stages. Once the public sector crippled down the private sector filled the vacuum through their extensive network of hospitals and clinics. The public and private health care systems run parallel with no central coordination or supervision. The fragmented nature and the infrastructural disparity in the Indian public and private health care system are given in Table 1 and Table 2, respectively.

Table 1. Composition of Public and Private Health Care Sector

\begin{tabular}{|l|l|l|}
\hline $\begin{array}{l}\text { Heterogeneous } \\
\text { nature }\end{array}$ & Public & Private \\
\hline $\begin{array}{l}\text { Nature of } \\
\text { provider }\end{array}$ & Government Establishment & $\begin{array}{l}\text { A private company, trust, } \\
\text { cooperatives, partnership, Individual } \\
\text { providers including qualified and } \\
\text { unqualified persons }\end{array}$ \\
\hline $\begin{array}{l}\text { Nature of } \\
\text { Service }\end{array}$ & $\begin{array}{l}\text { Sub-Centres, Primary Health } \\
\text { Centres, Community Health } \\
\text { Centres, District Hospitals and } \\
\text { Medical Colleges }\end{array}$ & $\begin{array}{l}\text { Hospitals, maternity and nursing } \\
\text { homes, clinics, dispensaries, } \\
\text { traditional practitioners }\end{array}$ \\
\hline $\begin{array}{l}\text { Systems of } \\
\text { Care }\end{array}$ & Formal (Allopathic and AYUSH) & $\begin{array}{l}\text { Formal (Allopathy, Ayurveda, Unani, } \\
\text { Sidha, Homeopathy, Naturopathy), } \\
\text { Informal unqualified providers }\end{array}$ \\
\hline Ownership & Governmental & For-Profit and Not-for-Profit \\
\hline
\end{tabular}

Source: India Health Report, Oxford University Press 2003.

Table 2. Comparison of Growth of Public and Private Healthcare Infrastructure

\begin{tabular}{|l|l|l|l|l|}
\hline Provider & $1950-51$ & $1980-81$ & $2000-01$ & $2010-11$ \\
\hline Public & 9934 & 80918 & 206503 & 216286 \\
\hline Private & 1353 & 55271 & 400926 & 1035497 \\
\hline
\end{tabular}

Source: $10^{\text {th }}$ Five Year Plan, National Health Profile of India 2011, CBHI and Kumar, 2015

The private sector has grown without any regulatory controls. Hence there is no consolidated government-level statistics to show the total number of private clinical establishments functioning in India. The growth of the private sector was tremendous, and they are present both in rural and urban areas. It has grown from 1353 in 1950 to more than 10 lakh during the 2010-11 period. Among the private sector providers, the allopathic system dominates with a share of 76 percent. The percentage of Ayurveda and Homoeopathy is 7.4 percent and 11.2 percent, respectively(Kumar, 2015). On the other hand, the availability of public healthcare facilities is incredibly low in India, especially in rural areas.

A recent study conducted among women in India shows that the unavailability of public health care institutions increased from $27 \%$ to $42.4 \%$, low quality of care from $31.6 \%$ to $52.3 \%$, absence of health personnel from $4.9 \%$ to $16.8 \%$ during 2005-6 and 2015-16 periods (Bagchi et al., 2020). An independent study conducted in 2015 reveals the regional disparity existing in the availability of public and private health care facilities. In states like UP, West Bengal, Maharashtra, Kerala, Tamil Nadu, Andhra Pradesh etc. the private sector is powerful than in states like Arunachal Pradesh, Manipur, Sikkim, Nagaland etc. (Kumar, 2015). The private sector facilities are mostly skewed towards the urban areas, though they are present in rural areas. 
In India, though the successive governments projected healthcare and development of health infrastructure as priority areas, there is an acute shortage of public health facilities, doctors, nurses and other medical professionals. There is only one government doctor for 1139 patients and 0.7 beds for 1000 people in India (Abidi). All the more critical is, many of the existing facilities are not working optimally due to the unavailability of machines and health care personnel. The passive approach of government leaves the public sector to suffer, and it leads to the underutilisation of public health care facilities, and this turns beneficial to the private sector, which caters for the needs of more than 70 per cent of people in India.

\section{b. The utilisation of Public-Private Healthcare Services}

Due to the uncontrolled growth of private health care services both in rural and urban areas, and the unavailability of even essential services from the public health care facilities compelled a large majority of people across all income groups to avail services from the private health care facilities.

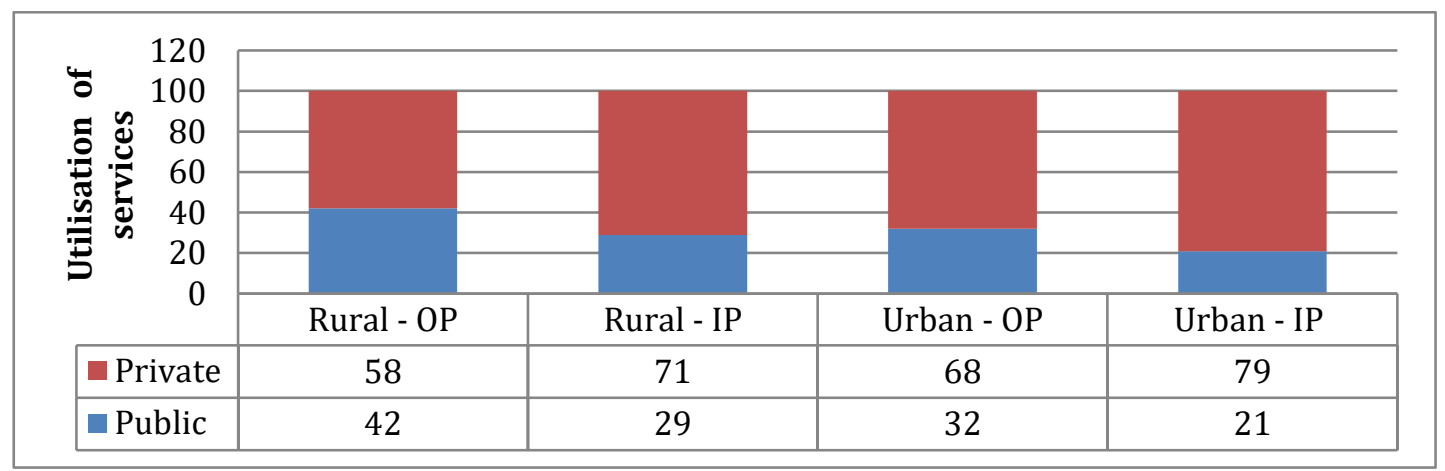

Figure 1. Utilisation pattern of public and private health care facilities in rural and urban areas

\section{Source: $71^{\text {st }}$ Round NSS 2014, NSSO}

The $71^{\text {st }}$ Round of National Sample Survey (NSS) explains the share of public and private sector establishments in India (Figure 1). More than 60 percent of rural and more than 70 percent of urban people are availing privatesector health care services. Also, it is important to note that $90 \%$ of people utilise the allopathic health care services and 5 to 7 percent of people utilise other systems of medicine (National Sample Survey Office, 2014). A recent study conducted among women in India shows a more disturbing trend that around 88 percent of their family members use private-sector facilities(Bagchi et al., 2020). There exists an inter-state variation in the utilisation of public and private health care services as well. In Assam and Odisha, people generally utilise public health care facilities with a share of 78 percent and 72 percent, respectively(National Sample Survey Office, 2014). The percentage of utilisation of the private sector is as high as more than 80 percent in Andhra Pradesh, Bihar, Telangana, UP, Haryana(National Sample Survey Office, 2014). In Gujarat, West Bengal, Chattisgarh, Jharkand, Kerala, Madhya Pradesh, Rajasthan and Tamil Nadu it is in between 60 percent to 80 percent. The higher rate of utilisation of private sector is due to the unavailability of a robust public health care system, lack of facilities, adequate of number health personnel, long waiting time, poor quality service etc.(Bagchi et al., 2020).

\section{c. The Public-Private disparity in Health Expenditure}

The backbone of any public healthcare system is the governmental share in health expenditure. On reviewing the health expenditure pattern in India, there can see a reverse trend. The total health expenditure of India was 4.0\% of Gross Domestic Product (GDP during 2003-04, and it drastically reduced after that. In the year 2016, it was only $3.5 \%$ of GDP. It is to be noted that the government is contributing around $1 \%$ of GDP, which is much lesser than that of the contribution of other lower-income countries and the countries in the Asian region ( 
Current Health Expenditure (CHE) as Percentage of Gross Domestic Product (GDP) (\%) - Data by WHO Region). A comparison of Public-Private Health Expenditure during 2009 - 2017 is given in Figure 2.

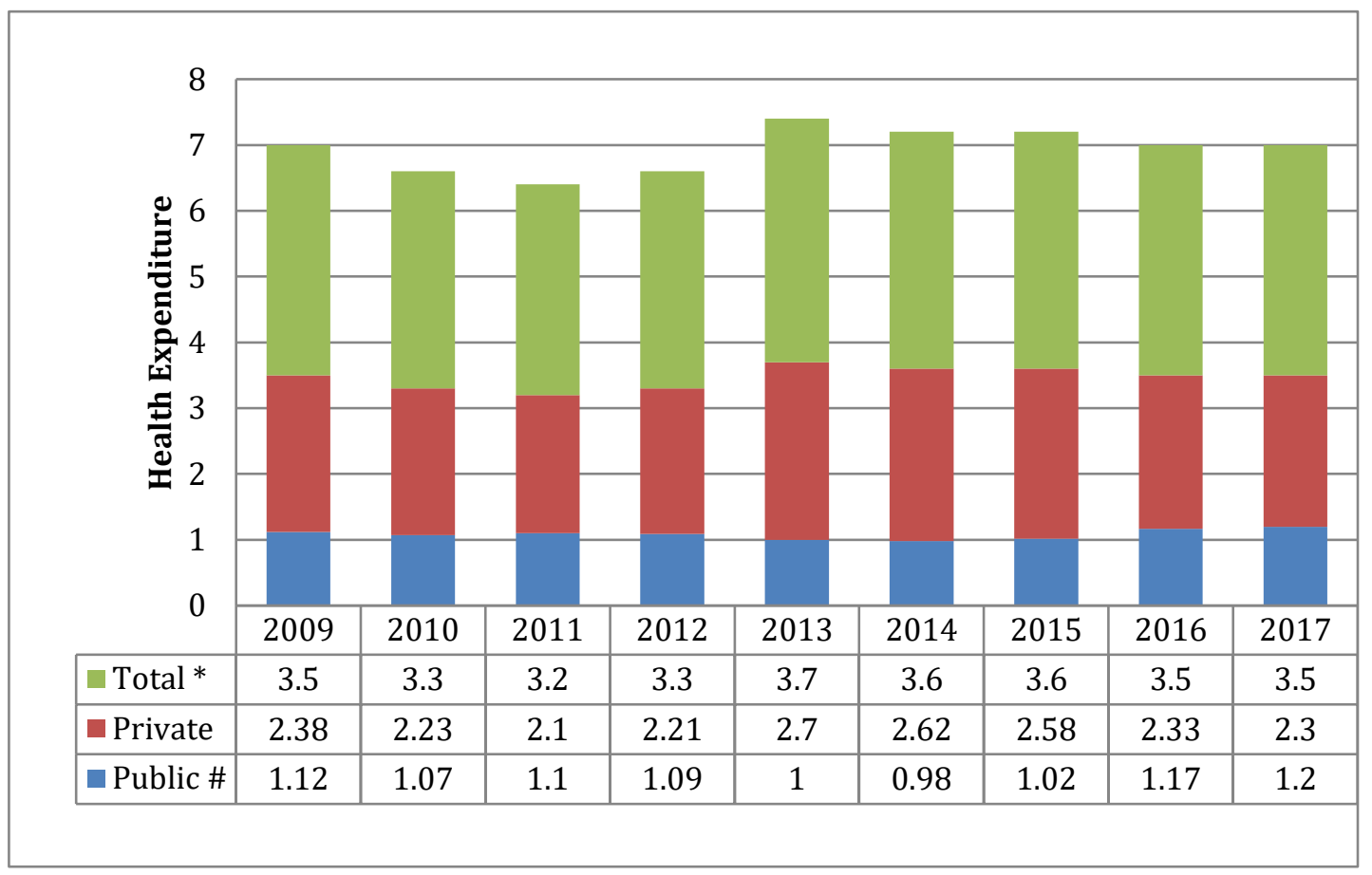

Figure No. 2. Comparison of the Public-Private Health Expenditure Pattern during 2009 - 2017

Source: *WHO Global Health data, \# National Health Profile 2019 and National Health Account, I2th Five Year Plan and Ibid

As per the latest report of the National Health Accounts Estimates for India 2016-17 released in October 2019, the GHE was 1.2 percent of GDP(Ministry On Health \& Family Welfare, 2019). The remaining 2.3 percent (the total health expenditure was $3.5 \%$ during 2016-17) was met by the private sector, which ultimately leads to catastrophic effects on low-income households. As per the report, 63.21 percent of health expenditure is met by families and the share of insurance is as low as 9.58 percent. The detail of the Health Expenditure pattern is given in Figure No. 3. 


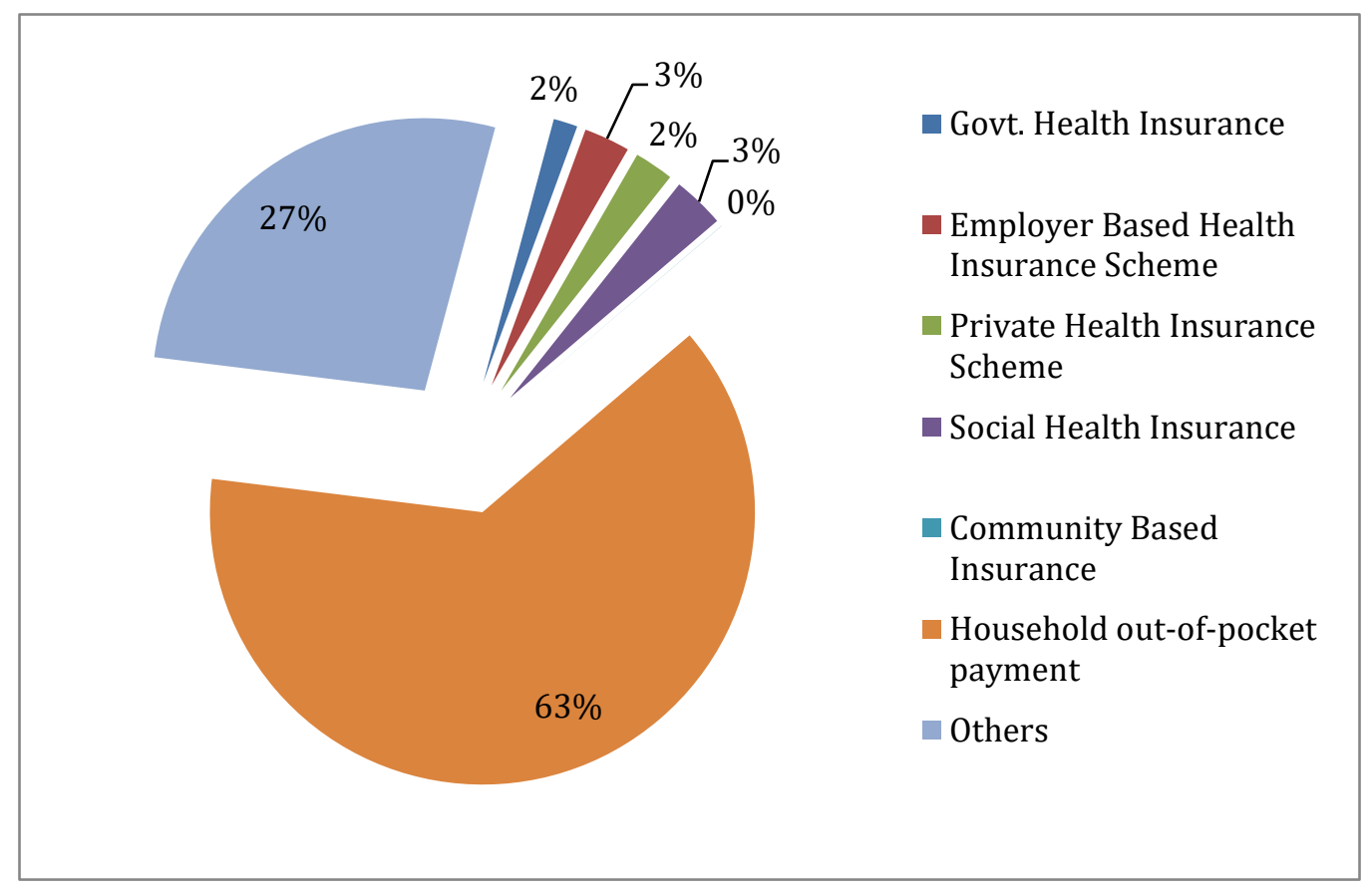

Figure 3. Health Expenditure Pattern 2016-17

Source: National Health Accounts Estimates for India 2016-17

The NSS ( $71^{\text {st }}$ Round) Report also reveals that around 57 percent of rural and 68 percent of urban people find financial constraints in seeking medical advice (National Sample Survey Office, 2014). For 67.8 percent rural and 74.9 percent urban people, the leading source of expenditure for hospitalisation is household income or savings. To meet the health expenditure, about 21.55 percent of people borrow money from others, and 0.6 percent of people sell their assets(Central Bureau of Health Intelligence, 2019). Due to the reduced GHE, the burden lies upon the households. The out-of-pocket expenditure pattern led to the skyrocketing of the medical cost. Taking this into account, the National Health Policy 2017 proposed to increase the Government Health Expenditure (GHE) to 2.5\% of GDP by 2025(Ministry of Health \& Family Welfare, 2017). Despite these promises and declarations, the GHE has not increased up to the proposed level.

\section{d. The Regulation of Public-Private Healthcare Establishments}

In India, the regulation of clinical establishments is an unending process. Since independence, though the private sector was present in the healthcare sector, a little effort was made to regulate them. The public and private healthcare sector providers functioned parallel to each other with no regulation of the private sector. There are no national standards for the geographical distribution of private health care facilities, quality of infrastructure, qualification of medical and paramedical professionals, standardisation of cost of medical care etc. In the Indian federal system, the law-making power on health is scattered over List I (Entry -58, 59, 81, 84), List II (Entry 6,7,8,10,14,17) and List III(Entry 3,5,16,18,19,24,25,28,29,30) of the Constitution of India. However, the power to enact legislation to regulate hospitals and dispensaries is provided in List II (Entry 6) of the Seventh Schedule. Hence the state legislatures are competent to enact legislation to regulate clinical establishments.

Though the regulatory power is vested upon the state governments, the Central Government enacted the first national-level legislation, the Clinical Establishments (Registration and Regulation) Act (CEA) in 2010 by exercising power under Article 252 of the Indian Constitution. Since it was enacted by the parliament using the power under Art. 252, its application is limited to states that have passed a special resolution for the adoption of 
the same. As of now, it applies to the states of Arunachal Pradesh, Himachal Pradesh, Uttar Pradesh, Sikkim, Mizoram, Bihar, Jharkhand, Rajasthan, Uttarakhand, Assam and Haryana and all U.T.s except Delhi. Since CEA is a central legislation, the state governments are being persuaded by the Central Government to adopt it. However, many states have enacted separate legislation for regulating clinical establishments. The state of Kerala adopted the Clinical Establishments (Registration and Regulation) Act in 2018. Other states like Tamil Nadu (The Tamil Nadu Clinical Establishments Act, 1997), Andhra Pradesh (Andhra Pradesh Allopathic Private Medical Care Establishments (Registration and Regulation) Act 2002 ), West Bengal (West Bengal Clinical Establishment (Registration, Regulation and Transparency) Act, 2017 etc. have separate legislations.

Though there are laws in many states, the provisions of these laws differ in its application level. Some are confined to allopathic systems/hospitals/private clinical establishments etc. In all these legislations, the regulatory framework revolves around the system of registration and licensing of clinical establishments. Though the registration and licensing are adopted as the regulatory measure by almost all states, there is no uniformity as to the conditions for granting/renewing/cancelling registration. The validity period of registration and license also differs. There is no uniformity in minimum standards prescribed by the state governments. The Clinical Establishments Act, 2010 also leaves no ray of hope in this regard. The implementation of national standards for clinical establishments is continuing as a dream. The most alarming fact is that almost 16 states have no proper regulations to control and ensure the minimum requirements of private healthcare facilities (Kumar, 2015). Thus the public-private dichotomy is more evident in the case of the essential need of bringing up a uniform regulatory framework.

\section{Implications of the Private - Public Dichotomy on National Digital Health Mission}

The NDHM is an encouraging initiative as it aims to ensure the availability of affordable health care to all, especially those who are in rural areas. The newly announced NDHM has triggered stakeholders at various levels, and its ramifications of the same are yet to come out. The digital health policies have generated discussion at different levels. This research article aims only to analyse how far the public-private dichotomy will be crucial in the implementation of NDHM.

\section{Need to review the working of the existing health care system}

Since independence, the successive governments in no time have attempted to study and understand the nature, system of management, utilisation pattern etc. of the private health care sector. Even in 2020, the responsible government authorities have no data on the number of private health care institutions functioning in the country. The lack of sufficient statistics of private health care providers deeply hinders the equity in health care service and a large section of the population in India find it difficult to get medical care even in emergency situations. Thus it is imperative to assess the geographically underserved localities, especially in rural areas to facilitate the proper allocation of resources. Since NDHM being a turning point in the history of Indian health care system, there shall be a review of the working of the private health care system to explore the availability of private sector in rural and urban areas, the pattern of utilisation, nature of services, nature of management etc. to devise more effective and beneficial policies in the health care sector and to streamline the digital health services in rural and urban areas.

\section{Ensuring the participation of private sector providers}

The private healthcare sector has always been reluctant to become part of any public health endeavours in India as there existed a compartmentalised public and private health care system. The private healthcare sector has surpassed the public healthcare sector in all means, especially in the case of infrastructure facilities. The total number of private sector institutions was more than ten lakhs in 2010-11, and it might have doubled by 2020 . The rural-urban and inter-state disparity in the availability of the private sector healthcare institutions is also evident. Thus compartmentalised approach needs to be restructured with the scope of maintaining a more 
balanced and sustainable healthcare system. Developing a digital ecosystem without the participation of the private sector will turn futile as the public sector hospitals and medical professionals are significantly less in number both in rural and urban areas. The primary objective of NDHM is to develop a unified digital health infrastructure with the participation of all stakeholders. One crucial component of the NDHM is a Health Facility Registry (HFR). The HFR intended to provide a repository of all health facilities in the public and private sector (NDHM). However, it is made entirely optional for the healthcare providers to become part of NDHM. Thus rather than leaving this to the private sector to determine, it should be taken as an opportunity by the government to contemplate a digital system with the participation of both public and private sector institutions to ensure equity in healthcare more specifically in digital healthcare.

\section{Utilisation pattern and predominance of single doctors clinics}

The private sector dominates not only in providing health care facilities; the utilisation trends both in rural and urban areas signify the need for envisaging a digital ecosystem with the participation of the private sector. The NSS ( $71^{\text {st }}$ Round) Report shows that private doctors are the primary source of medical care both in rural and urban areas with 50 percent share (National Sample Survey Office, 2014). Accommodating them in the digital network will be time-consuming, and any form of government imposition may discourage them from continuing their services. Which will either lead to more corporatisation or their space will remain vacant. In countries like U.S. digitalisation was implemented through incentivised government programmes (Burde, 2011). A similar attempt in India will bring a considerable burden upon the Indian exchequer. Leaving the digitalisation programme to the private sector will again lead to haphazard implementation. Thus models of public-private partnerships need to be encouraged to develop a digital ecosystem which is sustainable and productive.

\section{Training the medical and paramedical professionals}

Training the medical and paramedical professionals is equally important as that of developing the digital infrastructure. It is more perturbing in case of private-sector medical and paramedical professionals. Allowing the untrained medical staff (medical, nursing and paramedical) to offer digital health services will be detrimental to patients' safety and management of data and valuable health information. Amid COVID 19 the Board of Governors (BoG) in supersession of Medical Council of India released the telemedicine guidelines in August 2020. It is tweaked in as appendix 5 to the Indian Medical Council (Professional Conduct, Etiquette and Ethics Regulation, 2002 (Telemedicine Practice Guidelines - Enabling Registered Medical Practitioners to Provide Healthcare Using Telemedicine, 2020). As per the Guidelines 1.3.3. of the Telemedicine Practice Guidelines, any registered medical practitioner (RMP) offering telemedicine services shall compulsory attend a training course. However, no system has yet been developed to train a large number of health care providers in India especially those who are in the private sector as the Government lacks proper control over the private sector providers. More importantly, there is no overseeing authority other than the National Medical Commission and Medical Councils that are having limited powers on this matter. Thus it shall be made legally mandatory for the private and public sector medical and paramedical professionals to attend training courses.

\section{Accommodating different systems of medicine}

In India, the Allopathic system of medicine predominates in medical care. However, other systems of medicine like Ayurveda, Homoeopathy, Sidha, Naturopathy and Unani are also popular. Some private institutions have already stepped into the digital health world through teleconsultations. Any attempt to digitalise health care should address the issues of institutions functioning under other systems of medicine as well. As far as the providers under the different systems of medicine, there exist no valid data and the studies are scanty. Thus to figure out the reach of other systems of medicine a review of the health care providers who are offering services under other systems of medicine shall be initiated. Attempts must be made to prepare the stakeholders to 
understand the possibilities of digital health and to ensure their participation in public and digital health programmes.

\section{Need to improve GHE and reduce the burden of households}

Even after repeated efforts and declarations to increase the GHE, it is still staggering around one percent of GDP. The digitalisation of health care requires investing a massive amount in installing digital infrastructure and in developing data security measures. The COVID 19 exposed the dire need of having an efficient public health care system to provide affordable and quality medical care both in rural and urban areas. The digitalisation of the health care sector is not a panacea for all public health issues. Thus attempt to digitalise the health care system at the cost of public health initiatives cannot be welcomed. Indian care system is still evolving and has not yet reached a satisfactory level in protecting the fundamental rights of people. As it is going through privatisation and corporatisation of health care, the focus shall be to ensure the availability of affordable health care through public health care facilities and cost supporting measures rather than deviate from the track. It may delineate the primary objectives of equitable and affordable healthcare. The experiences in other countries shall be reviewed carefully and must-see how technical glitches reduced the initial attraction of digital health programmes in other countries (Abidi). Over thirty countries have initiated nationwide digital health adoption, but none of these countries has succeeded in implementing it thoroughly (Swaniti Initiative). Apart from digital health initiatives, the government must focus on increasing the GHE and developing better public infrastructure as more than 70 percent of people in India are using the private sector with no insurance protection.

\section{Lack of proper regulation for clinical establishments and telemedicine services}

In India, there is no uniformity in the regulation of clinical establishments in the private sector, and there exists no governmental level supervisory authority other than National Council established under the CEA 2010. But CEA 2010 has only limited application. Since regulation of clinical establishment is within the legislative power of the state governments, their approach will critical in digital health programmes. However, for developing a healthy and friendly national-level digital health ecosystem, proper regulations for maintaining minimum standards of digital health programmes, infrastructural facilities, qualification of healthcare personnel, preparation and maintenance of medical records of online consultations etc. are indispensable.

\section{Health Data Protection in Public and Private Sector}

In a digital health ecosystem, it is imperative to have measures for data security and adoption of Electronic Health Records (EHR) or Electronic Medical Records (EMR) or Personal Health Records (PHR). The CEA 2010 mandates for keeping EMR of patients by all clinical establishments registered under the Act. The Electronic Health Records Standards was adopted in 2016. But it lacks proper implementation. Apart from that, there is no law which mandates the maintenance of EHR in the private sector. More important, on the point of health data security in India at present provisions under the Information Technology Act, 2000 and Rules thereunder are applicable. However, in the broad digital health regime, the I.T. Act has only limited application. Hence two Bills were proposed on data security, The Personal Data Protection Bill, 2019 and the Digital Information Security in Healthcare Act (DISHA) 2017. The health data breach reported by the HIPAA in the U.S. is the fine example of having a robust data regulatory authority in a digital health ecosystem. In September alone, HIPAA reported 9.7 million data breaches (September 2020 Healthcare Data Breach Report: 9.7 Million Records Compromised.). The proposed NDHM envisages introducing common information stack for public and private sector providers. If so, lack of adequate regulatory norms for data protection may be disastrous, and it will ultimately pave the way for gross misuse of personal data of patients, especially those who are poor and underprivileged. Since many of the private sector establishments, mostly the large scale hospitals have already adopted EMR/ EHR, proper regulation is very much needed. Invariably such laws shall be made applicable to all public and private health care establishments. 


\section{Interoperability of information does not guarantee medical care}

Though the NDHM aims to ensure interoperability of information, it does not intend to provide any kind of medical service in the private sector for patients other than the beneficiaries under various government insurance schemes including Ayushman Bharat. The digital health initiatives do not assure medical care to more than 70 percent of the population in India who are using the private sector, and more than 80 percent of them are not covered under any insurance schemes. Thus along with facilitating the private sector to become part of the NDHM, they should be made responsible to respond positively to the health needs of the country especially during health emergencies.

\section{Safe digital ecosystem for global players}

Though India is preparing to get into the digital health wagon, many national and multinational entities have already launched their services in India. Since India is one of fast-growing healthcare market at the global level, the adoption of international standards will become integral to the NDHM. However, how far the global standards will be acceptable to the providers in India, especially the small scale and indigenous systems are to be addressed by the policymakers. Thus the policymakers have a two-fold responsibility to facilitate the participation of global players by providing a safe digital ecosystem and to encourage the local level small-scale providers to continue their services and to contribute to the new digital health initiatives.

\section{Stringent laws for medical errors and medical negligence}

In process of transforming the health care system, it is imperative to address issues of medical errors and medical negligence in online consultations. As of now, the medical negligence laws in India are governed under the common law principles of negligence, the Consumer Protection Act, 2019 and the Indian Penal Code, 1860. However, digital health infrastructure has a wider spectrum of cross-border providers and beneficiaries. In such a scenario, a proper legal regulatory framework shall be envisaged to address the grievances of patients in cases of medical errors and medical negligence.

\section{Conclusion}

The study finds that the Indian health care system is highly fragmented and heterogeneous. It has moved away from the fundamentals of a public health care system based on welfare principles. The successive governments in no time have attempted to establish a comprehensive health care system. Hence the public-private divide became more evident after the 1990s and the silent support of the government paved the way for a highly privatised health care system. In the Indian context of less number of public health care facilities and a reduced number of doctor-patient ratio, the digital health solutions is a welcome step. But the digital health paradigm demands higher GHE, better regulatory regime, comprehensive health care structure etc. In the current publicprivate disjunction, implementing NDHM without taking efforts to address the fundamental issues of publicprivate disjunction will turn futile. NDHM, as it is announced, made it voluntary for the private sector service providers to participate in the NDHM. Hence the lack of a framework to bring a comprehensive health care system will simply add upon existing public-private dichotomy, more precisely a digital divide in the health care sector. More important to note that this digital divide and lack of regulation will be detrimental to the patients' safety and security of health information. Thus it is suggested to address the public-private dichotomy by the policymakers and to reduce the public-private disjunction by developing an integrated and sustainable health care structure with the participation of the private sector providers including the corporate sector for ensuring the right to health of people. It includes a proper review of the existing health care facilities across the states in India in public and private sector under different systems of medicine and understanding their nature of healthcare services and the scope of integrating them in the new NDHM. There shall be a long-term vision based on a public private partnership to render service to geographically underserved areas through online 
consultations. Along with the endeavours to encourage the private sector to participate in various digital health programmes, the State must devise proper legal regulations to ensure the standards of online consultations, qualification of service providers, rights of patients, maintenance of medical records, data privacy etc. The government is also duty-bound to facilitate and streamline global service providers. These are very fundamental for the proper implementation of any new programmes like NDHM.

\section{References}

Abidi, A. F. (n.d.). Does India need a digital health mission?. The Wire Science. Retrieved October 24, 2020, from https://science.thewire.in/health/does-india-need-a-digital-health-mission/

Aryan, A., \& Mukul, P. (n.d.). Jio 5G explained: What does the solution mean to Reliance, and its users?.The Indian Express. Retrieved October 24, 2020, from https://indianexpress.com/article/explained/jio-5g-what-doesthe-solution-mean-to-reliance-and-its-users-6509088/

Bagchi, T., Das, A., Dawad, S., \& Dalal, K. (2020). Non-utilization of public healthcare facilities during sickness: a national study in India. Journal of Public Health: From Theory to Practice, 1-9. https://doi.org/10.1007/s10389-020-01363-3

Bhore, J., Amesur, R. A., Cotter, C. L. E., Dadabhoy, I. M. S.; D. J. R., Bombay, M. R. C. P. O. B. E., \& Member, M. L. A. (1946). Report of the Health Survey and Development Committee. Retrieved February 12, 2021, from https://www.nhp.gov.in/sites/default/files/pdf/Bhore_Committee_Report_VOL-1.pdf.

World Health Organization, Current health expenditure (CHE) as percentage of gross domestic product (GDP) (\%) - Data by WHO region. (n.d.). Retrieved February 12, 2021, from https://apps.who.int/gho/data/node.imr.GHED_CHEGDP_SHA2011?lang=en

Telemedicine Practice Guidelines - Enabling Registered Medical Practitioners to Provide Healthcare Using Telemedicine, (2020). Retrieved December 15, 2020, from https://www.mohfw.gov.in/pdf/Telemedicine.pdf.

Burde, H. (2011). The HITech Act-An overview. Virtual Mentor, 13(3), $172-175$. https://doi.org/10.1001/virtualmentor.2011.13.3.hlaw1-1103

Central Bureau of Health Intelligence. (2019). National Health Profile (NHP) of India- 2019. Retrieved from February 12, 2021, from http://www.cbhidghs.nic.in/showfile.php?lid=1147

'Digital Health: The future series II- bridging the gap: A.I..'s role in combating inequalities in health' webinar organised - express healthcare. (n.d.). Retrieved October 24, 2020, from https://www.expresshealthcare.in/news/digital-health-the-future-series-ii-bridging-the-gap-ais-role-incombating-inequalities-in-health-webinar-organised/422433/

Digital healthcare market in India 2019 - Research and markets. (n.d.). Retrieved October 24, 2020, from https://www.researchandmarkets.com/reports/4988978/digital-healthcare-market-in-india-2019

Duggal, R. (2004). Tracing privatisation of healthcare in India. Express Healthcare Management. Retrieved February 12, 2021, from https://www.researchgate.net/publication/236888943

Government of India. (1961). Third Five Year Plan (1961-66). Retrieved November 14, 202, from https://niti.gov.in/planningcommission.gov.in/docs/plans/planrel/fiveyr/3rd/3planch32.html

Government of India. (2013). Twelfth Five Year Plan (2012-17). Retrieved February 12, 2021, from www.sagepub.in

Healthcare industry in india (n.d.). Retrieved October 24, 2020, from https://www.ibef.org/industry/healthcareindia.aspx

Kumar, S. (2015). Private sector in healthcare delivery market in India: Structure, Growth and Implications. Retrieved November 20, 2020, from http://111.93.232.162/pdf/WP185.pdf

Labrique, A. B., Wadhwani, C., Williams, K. A., Lamptey, P., Hesp, C., Luk, R., \& Aerts, A. (2018). Best practices in scaling digital health in low and middle income countries. Global Health 14. https://doi.org/10.1186/s12992-018-0424-z 
Marathe, S., Hunter, B. M., Chakravarthi, I., Shukla, A., \& Murray, S. F. (2020). The impacts of corporatisation of healthcare on medical practice and professionals in Maharashtra, India. BMJ Global Health, 1-5. https://doi.org/10.1136/bmjgh-2019-002026

Mathur, N. (n.d.). MeitY and Google tie up to build for digital India. Retrieved October 24, 2020, from https://www.livemint.com/news/india/meity-and-google-tie-up-to-build-for-digital-india-1567249514749.html

McGrail Samantha. (n.d.). 88\% of providers investing in remote patient monitoring Tech. Retrieved October 24, 2020, from https://mhealthintelligence.com/news/88-of-providers-investing-in-remote-patient-monitoring-tech

Ministry of Health \& Family Welfare. (2017). National Health Policy 2017. Retrieved February 12, 2021, from https://www.nhp.gov.in/nhpfiles/national_health_policy_2017.pdf

Ministry of Health \& Family Welfare. (2019). National Digital Health Blueprint (NDHB). Retrieved February 12, 2021, from https://main.mohfw.gov.in/sites/default/files/Final Report - Lite Version.pdf

Ministry of Health and Family Welfare. (1983). National Health Policy 1983. Retrieved February 11, 2021, from https://www.nhp.gov.in/sites/default/files/pdf/nhp_1983.pdf

Ministry On Health \& Family Welfare. (2019). National Health Accounts Estimates for India 2016-17. $\begin{array}{llll}\text { Retrieved } & \text { February } & 10, & \text { 2021, from }\end{array}$ http://nhsrcindia.org/sites/default/files/FINAL\%20National\%20Health\%20Accounts\%20201617\%20Nov\%202019-for\%20Web.pdf

National Health Mission: National Digital Health Mission rolled out on pilot mode in 6 union territories, Times of India. (n.d.). Retrieved October 24, 2020, from https://timesofindia.indiatimes.com/india/national-digitalhealth-mission-rolled-out-on-pilot-mode-in-6-union-territories/articleshow/77565648.cms

National Health Portal of India, Gateway to Authentic Health Information. (n.d.). Retrieved October 24, 2020, from https://www.nhp.gov.in/

National Sample Survey Office. (2014). NSS 71st Round - Health in India. http://mospi.nic.in/sites/default/files/publication_reports/nss_rep574.pdf

NDHM. (n.d.). Retrieved October 25, 2020, from https://ndhm.gov.in/

NITI Aayog. (2019). Health system for a new India: Building blocks . Retrieved November 28, 2020, from https://niti.gov.in/sites/default/files/2019-11/NitiAayogBook_compressed.pdf

Schwab Klaus. (n.d.). The fourth industrial revolution: What it means and how to respond, World Economic Forum. Retrieved October 24, 2020, from https://www.weforum.org/agenda/2016/01/the-fourth-industrialrevolution-what-it-means-and-how-to-respond/

September 2020 Healthcare data breach report: 9.7 million records compromised. (n.d.). Retrieved October 25 , 2020, from https://www.hipaajournal.com/september-2020-healthcare-data-breach-report-9-7-million-recordscompromised/

Sharma Neetu Chandra. (n.d.). PM Modi launches National Digital Health Mission. Retrieved October 24, 2020 , from https://www.livemint.com/news/india/pm-modi-launches-national-digital-health-mission11597467562654.html

Singh S. (n.d.). Philips' 2019 future health index report: Digital health technology ups the game. Retrieved October 24, 2020, from https://indiamedtoday.com/philips-2019-future-health-index-report-digital-healthtechnology-ups-the-game/

Swaniti Initiative. (n.d.). Health records system in India. Retrieved October 25, 2020, from http://www.swaniti.com/wp-content/uploads/2016/02/Health-records-system-in-India.pdf

U.N. Office of the High Commissioner for Human Rights (OHCHR). (2008). Fact Sheet No. 31, The right to health. Retrieved December 20, 2020, from https://www.refworld.org/docid/48625a742.html

Vaidyanathan Baru, R. (n.d.). Privatisation of health care in India : A comparative analysis of Orissa, Karnataka and Maharashtra states. In CMDR Monograph Series (p. 43). Retrieved February 12, 2021, from http://cmdr.ac.in/editor_v51/assets/mono-43.pdf 
WHO releases first guideline on digital health interventions. (n.d.). Retrieved October 24, 2020, from https://www.who.int/news/item/17-04-2019-who-releases-first-guideline-on-digital-health-interventions

World Health Organization. (2019). WHO Guideline: Recommendations on digital interventions for health $\begin{array}{lllll}\text { system } \quad \text { strengthening. } & \text { Retrieved } & \text { December } & 2620, & \text { from }\end{array}$ https://www.who.int/publications/i/item/978924155050-5 